\title{
KESESUAIAN JENIS MURBEI DAN BIOFISIK DAERAH KERING SULAWESI SELATAN
}

(Compatibility of Mulberry with Its Soils's Biophysics at Dry Area of South Sulawesi)

Oleh/By:

Budi Santoso, Bintarto Wahyu Wardani, dan/and Retno Prayudyaningsih

\begin{abstract}
The objectives of this research were to know compatibility of mulberry, rainfall and physical and chemical of soil at silk development area in South Sulawesi during dry season. This research was conducted at Lawowoi (Sidrap regency) and Sabangparu (Wajo regency). Each location was divided into three blocks and each block consisted of nine mulberry species/varieties. The observed parameter was: leaf productivity, rainfall and soil physical and chemical. Morus khunpai K. produced very high leaf productivity in Wajo and Sidrap that was $193.67 \mathrm{~g} /$ tree in Wajo and $194.00 \mathrm{~g} / \mathrm{tree}$ in Sidrap. Rainfall in Lawowoi (Sidrap) and Sabbangparu (Wajo) was low, so that it less supported for the growth of mulberry. Soil in Lawowoi was suitable for mulberry, but it must be added with other fertilizers such as nitrogen, calcium and phosphor. On the other hand soil in Sabbangparu must be fertilized with the nitrogen, calcium and phosphor and also its soil texture musi be improved.
\end{abstract}

Key words: Mulberry, species compatibility, dry area

\section{ABSTRAK}

Penelitian ini bertujuan untuk mendapatkan informasi tentang kesesuaian jenis murbei, curah hujan, dan fisik serta kimia tanah daerah pengembangan persuteraan alam di Sulawesi. Selatan pada musim kemarau. Penelitian dilaksanakan di dua lokasi yaitu Lawowoi (Kabupaten Sidrap) dan Sabbangparu (Kabupaten Wajo). Pada setiap lokasi dibagi menjadi tiga blok dan setiap blok terdiri atas sembilan jenis/varietas murbei. Parameter yang diamati adalah produktivitas daun, curah hujan, sifat fisik dan kimia tanah. Produksi daun tertinggi di Wajo dan Sidrap dihasilkan oleh Morus khunpai K. yaitu 193,67 g/tanaman di Wajo dan 194,00 g/tanaman di Sidrap. Curah hujan di Lawowoi (Sidrap) dan Sabbangparu (Wajo) rendah, sehingga kurang mendukung untuk pertumbuhan tanaman murbei. Tanah di Lawowoi layak digunakan untuk budidaya tanaman murbei, namun harus ditarnbahkan pupuk nitrogen, kalsium, dan posfor. Sedang tanah di Sabbangparu harus dipupuk dengan nitrogen, kalsium, dan posfor serta diperbaiki tekstur tanahnya.

Kata kunci : Murbei, kesesuaian jenis, daerah kering

\section{PENDAHULUAN}

\section{A. Latar Belakang}

Pada awal budidaya tanaman murbei di Indonesia hanya lima jenis tanaman murbei yang sudah dikenal dan dibudidayakan yaitu Morus nigra L., Morus alba L., Morus australis, Morus cathayana M., dan Morus multicaulis M. (Atmasoedarjo et.al, 2000). Namun dalam perkembangannya cukup banyak murbei eksot yang diintrodusir ke Indonesia, misalnya Morus indica S-54, Morus canva II, dan Morus khunpai $\mathrm{K}$. Di Sulawesi Selatan terdapat 13 jenis/ varietas murbei yang dibudidayakan ma- syarakat, namun $70 \%$ petani sutera alam di daerah ini membudidayakan Morus nigra L. dan Morus alba L. Kedua jenis murbei ini memiliki kelebihan dalam kemudahan pembudidayaannya.

Suhu optimal untuk pertumbuhan murbei adalah antara $23,9^{\circ} \mathrm{C}$ sampai $26,6^{\circ} \mathrm{C}$ walaupun murbei dapat tumbuh baik pada daerah dengan suhu di atas $13^{\circ} \mathrm{C}$ dan di bawah $37,7^{\circ} \mathrm{C}$. Curah hujan yang diperlukan untuk pertumbuhan murbei adalah antara 635-2.500 $\mathrm{mm}$ per tahun. Murbei dapat ditumbuhkan di berbagai macam tanah, dengan syarat keseimbangan antara suhu udara, kelembaban, dan hara dalam keadaan cukup 
(Soeseno dan Na'iem, 1995). Di Sulawesi Selatan memiliki lahan cukup luas untuk pengembangan persuteraan alam, namun tidak semua berpotensi mendukung pertumbuhan tanaman murbei secara maksimal. Di daerah ini, umumnya lahan tanaman murbei pada lereng bukit, tanahnya miskin hara, curah hujan rendah, dan ketinggian tempat dari permukaan laut rendah, sehingga kurang mendukung pertumbuhan tanaman murbei.

Lahan tanaman murbei di Sulawesi Selatan seluas 3.321 ha tersebar di 13 kabupaten yaitu Enrekang, Soppeng, Wajo, Sidrap, Barru, Bone, Tana Toraja, Polmas, Luwu, Gowa, Sinjai, Bulukumba, Bantaeng, dan Maros (Hartoko, 2002). Daerah yang dari segi kesesuaian lahan menunjang pertumbuhan tanaman murbei adalah Kabupaten Enrekang dan Kabupaten Tana Toraja. Beberapa daerah walaupun dari sisi kesesuaian lahan kurang cocok untuk tanaman murbei, namun secara budaya telah mengembangkan persuteraan alam seperti Kabupaten Soppeng, Kabupaten Wajo, dan Kabupaten Sidrap.

Kebijakan pemerintah dalam mengatasi rendahnya produktivitas kebun murbei di Indonesia adalah penggunaan jenis unggul dan peningkatan intensifikasi bercocok tanam murbei. Sampai saat ini bibit murbei unggul didatangkan dari negara-negara sub tropis yang maju persuteraan alamnya misalnya Jepang, India, dan Cina. Murbei eksot ini belum sepenuhnya dapat mengatasi rendahnya produktivitas kebun murbei di Indonesia, dikarenakan kondisi tempat tumbuh, iklim, dan pola budidaya murbei yang berbeda. Penampilan yang paling berbeda pada saat musim kemarau, di India produktivitas daunnya turun 30-45\% sedang di Sulawesi Selatan menurun 30-70\% (Santoso, 2002).

Salah satu upaya yang dapat ditempuh untuk mengatasi kendala tersebut di antaranya adalah mengkhususkan setiap jenis murbei pada masing-masing wilayah pengembangan. Diharapkan dengan hal tersebut produktivitas kebun murbei di Sulawesi dapat ditingkatkan. Di antara daerah pengembangan persuteraan alam di Sulawesi Selatan yang memiliki bulan kering lebih panjang dibanding bulan basah adalah Kabupaten Sidrap dan Kabupaten Wajo, seharusnya kedua wilayah ini jenis murbei yang dibudidayakan adalah jenis-jenis yang memiliki ketahanan kekeringan yang optimal.

\section{B. Tujuan Penelitian}

Tujuan dari penelitian ini adalah untuk mendapatkan informasi tentang kesesuaian jenis murbei, curah hujan, dan fisik serta kimia tanah daerah pengembangan persuteraan alam di Lawowoi (Kabupaten Sidrap) dan Sabbangparu (Kabupaten Wajo) Sulawesi Selatan pada musim kemarau.

\section{METODE PENELITIAN}

\section{A. Waktu dan Lokasi Penelitian}

Kegiatan penelitian ini dilakukan pada saat musim kemarau dari bulan Juli sampai Oktober 2003. Rincian kegiatan adalah sebagai berikut :

1. Akhir bulan Juli 2003 dilakukan pemangkasan dengan tinggi pangkasan $40 \mathrm{~cm}$ dari tanah, wiwilan cabang tak produktif, pendangiran tanaman yang akan diamati, pembagian blok, dan pelabelan.

2. Bulan Agustus sampai dengan Oktober dilakukan pengamatan, terutama pada akhir bulan Oktober 2003 dilakukan pemanenan daun, pengamatan tanah, dan pengambilan data iklim.

Penelitian ini dilaksanakan di Lawowoi (Kabupaten Sidrap) dan Sabbangparu (Kabupaten Wajo). Lokasi pengamatan tersebut merupakan kebun percobaan tanaman murbei dari Balai Persuteraan Alam Bili-Bili Sulawesi Selatan. Deskripsi lengkap lokasi penelitian tersaji pada Tabel 1. 
Tabel (Table) 1. Deskripsi lokasi penelitian (Description of the field study)

\begin{tabular}{lcc}
\hline \multicolumn{1}{c}{$\begin{array}{c}\text { Parameter } \\
\text { (Parameters) }\end{array}$} & $\begin{array}{c}\text { Kabupaten Wajo } \\
\text { (Wajo Regency) }\end{array}$ & $\begin{array}{c}\text { Kabupaten Sidrap } \\
\text { (Sidrap Regency) }\end{array}$ \\
\hline Tipe iklim (Climate type) & $\mathrm{C}$ & $\mathrm{C}$ \\
Ketinggian (Altitude) & $200 \mathrm{~m} \mathrm{dpl}$ & $200 \mathrm{~m} \mathrm{dpl}$ \\
Bulan basah (Wet season) & $3 \mathrm{bulan}$ & $3 \mathrm{bulan}$ \\
Bulan kering (Dry season) & $5 \mathrm{bulan}$ & $5 \mathrm{bulan}$ \\
Rerata curah hujan (Rainfall average) & $996 \mathrm{~mm} / \mathrm{tahun}$ & $1251 \mathrm{~mm} / \mathrm{tahun}$ \\
pH tanah (Soil $\mathrm{pH}$ ) & 6,21 & 6,28 \\
\hline
\end{tabular}

\section{B. Bahan dan Peralatan}

Bahan penelitian yang digunakan adalah tanaman murbei yang berumur tiga bulan dari pangkasan. Tanaman tersebut telah berumur lima tahun, dengan jarak tanam $2 \mathrm{~m} \times 1 \mathrm{~m}$. Pada Tabel 2 disajikan jenis-jenis murbei setiap lokasi penelitian.

Tabel (Table) 2. Jenis-jenis murbei yang diamati di Wajo dan Sidrap Sulawesi Selatan (Some of observed mulberry species at Wajo and Sidrap South Sulawesi)

\begin{tabular}{|c|c|c|}
\hline No & $\begin{array}{r}\text { Kabupaten Sidrap } \\
\text { (Sidrap Regency) }\end{array}$ & $\begin{array}{l}\text { Kabupaten Wajo } \\
\text { (Wajo Regency) }\end{array}$ \\
\hline 1 & M. khunpai K. & M. khunpai $\mathrm{K}$. \\
\hline 2 & BNK3 & M. alba L. \\
\hline 3 & Rajawali (Morus sp.) & M. indica S-54 \\
\hline 4 & M. indica $S-54$ & M. cathayana M. \\
\hline 5 & M. alba L. & Rajawali (Morus sp.) \\
\hline 6 & M. cathayana M. & M. acidosa $\mathrm{G}$. \\
\hline 7 & M. acidosa $\mathrm{G}$. & BNK3 \\
\hline 8 & M. nigra L. & M. nigra L. \\
\hline 9 & M. multicaulis $\mathrm{P}$. & M. multicaulis $\mathrm{P}$. \\
\hline
\end{tabular}

Peralatan penelitian yang digunakan antara lain gunting stek, mistar, timbangan, gelas ukur, sprayer tangan, cangkul, dan oven.

\section{Rancangan Penelitian}

Penelitian dilaksanakan di dua lokasi yaitu Lawowoi dan Sabbangparu. Pada setiap lokasi dibagi menjadi tiga blok, setiap blok terdiri atas sembilan jenis/ varietas murbei dengan ulangan 25 tanaman. Umur tanaman lima tahun dan pemeliharaan yang dilakukan seragam mulai saat penanaman dan kegiatan pemeliharaan dilakukan setiap tiga bulan. Parameter yang diamati adalah :
1. Produktivitas daun, dihitung dengan jalan menimbang jumlah daun pada akhir pengamatan (umur tiga bulan dari pangkasan).

2. Data curah hujan.

3. Data tanah, meliputi pembuatan profil tanah dan pengambilan sampel tanah untuk dianalisis sifat fisik dan kimianya.

\section{Analisis Data}

Data hasil pengamatan kemudian ditabulasi, selanjutnya untuk setiap tempat dibandingkan antar jenis murbei dengan analisis varian pada parameter produksi daun. Untuk mengetahui kombinasi yang berbeda dilakukan uji lanjutan LSD, dengan formulasinya sebagai berikut :

$\mathrm{LSD}=\mathrm{t} \alpha / 2 \sqrt{ } 2 \mathrm{KTe} / \mathrm{n}$

Dimana :

$\mathrm{t} \alpha / 2=$ nilai tabel $\mathrm{t}$ pada derajat bebas error

$\mathrm{KTe}=$ kuadrat tengah error

$\mathrm{N}=$ ulangan

\section{HASIL DAN PEMBAHASAN}

\section{A. Produksi Daun Tanaman Murbei}

Hasil analisis varian produksi daun tanaman murbei di Kabupaten Wajo dan Kabupaten Sidrap pada musim kemarau menunjukkan terjadinya perbedaan produksi daun antar jenis tanaman murbei. Hasil ini didukung hasil penelitian yang dilakukan oleh Samsijah (1992) dan Santoso (1996) yang menunjukkan di antara jenis tanaman murbei terjadi variasi produksi daun. Pada Tabel 3 disajikan hasil uji lanjutannya. 
Tabel (Table) 3. Uji LSD produksi daun jenis-jenis murbei di Kabupaten Wajo dan Kabupaten Sidrap Sulawesi Selatan (LSD test of leaf production for some mulberries at Wajo and Sidrap Regency South Sulawesi)

\begin{tabular}{|c|c|c|c|c|c|}
\hline \multirow{2}{*}{$\begin{array}{l}\text { Jenis murbei } \\
\text { (Mulberry species) } \\
\text { M. alba L. }\end{array}$} & \multicolumn{2}{|c|}{$\begin{array}{c}\text { Produksi daun/tanaman (g) } \\
\text { di Kabupaten Wajo } \\
\text { (Leaf production/tree at } \\
\text { Wajo Regency) }\end{array}$} & \multirow{2}{*}{$\begin{array}{c}\begin{array}{c}\text { Jenis murbei } \\
(\text { Mulberry } \\
\text { Species })\end{array} \\
\text { M. acidosa } \mathrm{G} .\end{array}$} & \multicolumn{2}{|c|}{$\begin{array}{c}\text { Produksi daun/tanaman (g) } \\
\text { di Kabupaten Sidrap } \\
\text { (Leaf production/tree at } \\
\text { Sidrap Regency) }\end{array}$} \\
\hline & 35,40 & $\mathrm{a}$ & & 26,67 & $\mathrm{a}$ \\
\hline M. indica S-54 & 57,00 & $a b$ & M. indica S-54 & 39,67 & $a b$ \\
\hline M. cathayana M. & 74,25 & abc & M. cathayana M. & 60,67 & $a b c$ \\
\hline Rajawali & 89,00 & bcd & BNK3 & 67,00 & abcd \\
\hline M. acidosa $\mathrm{G}$. & 91,75 & bcde & M. nigra $\mathrm{L}$. & 69,67 & abcde \\
\hline BNK3 & 102,50 & bcde & M. alba L. & 74,67 & abcdef \\
\hline M. nigra $\mathrm{L}$ & 103,30 & bcde & Rajawali & 86,67 & abcdefg \\
\hline M. multicaulis $\mathrm{P}$. & 110,00 & bcde & M. multicaulis $\mathrm{P}$. & 99,67 & abcdefg \\
\hline M. khunpai K. & 193,67 & $\mathrm{f}$ & M. khunpai K. & 194,00 & $\mathrm{~g}$ \\
\hline
\end{tabular}

Hasil perbandingan produksi daun sembilan jenis/varietas murbei pada musim kemarau di Kabupaten Wajo menunjukkan bahwa $M$. khunpai produksi daunnya tertinggi. Produksi daun M. khunpai sebesar 193,67 g per tanaman ini berbeda dengan jenis murbei lainnya. Sedang $M$. alba dan $M$. indica S-54 yang banyak dibudidayakan masyarakat di Kabupaten Wajo produksi daunnya terendah yaitu $35,40 \mathrm{~g}$ per tanaman dan $57,00 \mathrm{~g}$ per tanaman. $M$. nigra produksi daunnya mencapai $103,30 \mathrm{~g}$ per tanaman berada pada ranking ke-3, hanya di bawah $M$. multicaulis dan $M$. khunpai. Murbei yang banyak diintrodusir masyarakat ( $M$. indica S-54) menduduki ranking ke-8 (57,00 g/pohon) dari sembilan jenis. Apabila petani di Kabupaten Wajo menanam murbei jenis $M$. khunpai, maka produktivitas kebun murbei masyarakat akan meningkat sebesar $239,77 \%$ apabila dibandingkan dengan $M$. indica S-54, dan akan meningkat sebesar 447,01\% apabila dibandingkan dengan $M$. alba.

Hasil perbandingan produksi daun sembilan jenis/varietas murbei di Lawowoi pada musim kemarau menunjukkan bahwa $M$. khunpai produksi daunnya tertinggi (194,00 g/tanaman). Hasil ini hampir sama dengan di Wajo $(193,67 \mathrm{~g} /$ tanaman) dan berbeda dengan jenis murbei lainnya. Murbei yang banyak diintrodusir masyarakat ( $M$. indica $\mathrm{S}-54)$ menduduki ranking ke delapan, $M$. nigra ranking ke lima, dan $M$. alba ranking ke empat. Apabila masyarakat di daerah Sidrap menanam $M$. khunpai maka produktivitas kebun murbeinya meningkat 389,03\% dibandingkan dengan menanam $M$. indica S-54 dan akan meningkat $159,8 \%$ apabila dibandingkan $M$. alba.

Apabila diperbandingkan produksi daun murbei di Kabupaten Sidrap dengan Kabupaten Wajo, rerata produksi daun di Kabupaten Sidrap lebih tinggi, kecuali $M$. khunpai, namun hanya selisih $0,33 \mathrm{~kg}$ / tanaman. $M$. khunpai nampaknya lebih layak dikembangkan di daerah yang memiliki musim kemarau lebih panjang, seperti Sidrap dan Wajo. Jenis murbei ini produksi daun pada musim penghujan juga cukup menjanjikan, menurut Santoso (2002) produksi daun M. khunpai. pada musim penghujan dapat mencapai 226,5 . $340,0 \mathrm{~g} /$ tanaman.

\section{B. Curah Hujan}

Rendahnya produktivitas tanaman murbei pada musim kemarau di Kabupaten Wajo dan Kabupaten Sidrap karena kegiatan persuteraan alam terkonsentrasi di lokasi yang beriklim kering yaitu 
dalam satu tahun terdapat bulan kering selama lima bulan dan bulan basah hanya tiga bulan. Hal ini menjadi kendala dalam budidaya tanaman murbei, karena tanaman murbei yang berasal dari daerah sub tropis menghendaki ketersediaan air yang cukup. Hasil pengamatan rerata musim hujan di Sabbangparu (Kabupaten Wajo) dan Lawowoi (Kabupaten Sidrap) tersaji pada Tabel 4.

Idealnya daerah pengembangan tanaman murbei curah hujannya adalah $2.500 \mathrm{~mm} / \mathrm{tahun}$, sedang di Kabupaten Wajo saat tahun penelitian curah hujan hanya mencapai $966 \mathrm{~mm} /$ tahun. Curah hujan di Kabupaten Wajo (966 mm/ tahun) lebih rendah dibandingkan di Kabupaten Sidrap (1.251 mm/tahun), sehingga rerata produksi daun varietas murbei di Kabupaten Wajo lebih rendah dibandingkan di Kabupaten Sidrap. Naboyuki (1983) mengatakan daerah yang memiliki curah hujan yang rendah perlu diairi agar tanaman murbei tumbuh optimal, karena tanaman murbei tidak tahan terhadap kekurangan air. Nampaknya kegiatan pengairan kebun murbei di Kabupaten Wajo dan Kabupaten Sidrap sulit dilaksanakan, sehingga pemilihan jenis murbei yang cocok dikembangkan di daerah yang beriklim kering sebagaimana di Kabupaten Wajo dan Kabupaten Sidrap, merupakan tindakan yang paling tepat. Zobel dan Talbert (1984) mengatakan pemilihan jenis yang tepat di daerah pengembangan akan dapat menghindari kesalahan mendasar akibat efek interaksi genotip lingkungan yang cukup besar.

\section{Sifat Fisik dan Kimia Tanah}

Hasil analisis tanah di lokasi Sabbangparu (Kabupaten Wajo) dan Lawowoi (Kabupaten Sidrap) tersaji pada Tabel 5.

Tabel 5 menunjukkan pada umumnya keasaman tanah sesuai untuk tanaman murbei, baik di Wajo dan Sidrap yaitu $\mathrm{pH}$ menuju netral $(6,21)$. Menurut Soeseno dan Na'iem (1995) keasaman tanah untuk tanaman murbei berkisar enam. Namun untuk C organik, posfor, dan $\mathrm{N}$ total rendah, menurut Rangaswami dan Jolly (1976) dan JOCV (1975) ketiga unsur ini sangat dibutuhkan untuk mendukung pertumbuhan daun murbei. Oleh karena itu untuk meningkatkan pertumbuhan dan produksi daun tanaman murbei di Kabupaten Wajo dan Kabupaten Sidrap pemupukan harus dilakukan setiap periode.

Kalium dan kalsium berperan dalam mendukung pertumbuhan tanaman teruta-

Tabel (Table) 4. Rerata curah hujan bulanan di Kabuapten Wajo dan Kabupaten Sidrap Sulawesi Selatan (The mean of monthly rainfall at Wajo and Sidrap Regency South Sulawesi)

\begin{tabular}{lcccc}
\hline \multirow{2}{*}{ Bulan (Month) } & \multicolumn{5}{c}{ Curah hujan (Rainfall) (mm) } \\
\cline { 2 - 5 } & \multicolumn{3}{c}{ Wajo } & Sidrap \\
\cline { 2 - 5 } & $\begin{array}{c}\text { Curah hujan } \\
\text { (Rainfall) }\end{array}$ & $\begin{array}{c}\text { Hari hujan } \\
\text { (Daily rain) }\end{array}$ & $\begin{array}{c}\text { Curah hujan } \\
\text { (Rainfall) }\end{array}$ & $\begin{array}{c}\text { Hari hujan } \\
\text { (Daily rain) }\end{array}$ \\
\hline Januari & 68 & 10 & 102 & 11 \\
Februari & 91 & 10 & 45 & 3 \\
Maret & 151 & 5 & 168 & 9 \\
April & 266 & 9 & 124 & 10 \\
Mei & 35 & 4 & 328 & 9 \\
Juni & 13 & 3 & 201 & 10 \\
Juli & 0 & 0 & 1 & 1 \\
Agustus & 39 & 3 & 0 & 0 \\
September & 16 & 3 & 13 & 2 \\
Oktober & 71 & 12 & 0 & 0 \\
November & 91 & 10 & 160 & 8 \\
Desember & 155 & 14 & 109 & 13 \\
\hline Jumlah (Total) & 996 & & 1.251 & \\
\hline
\end{tabular}


Tabel (Table) 5. Hasil analisis tanah di Kabupaten Wajo dan Kabupaten Sidrap Sulawesi Selatan (Result of soil analysis at Wajo and Sidrap Regency South Sulawesi)

\begin{tabular}{|c|c|c|c|c|}
\hline \multirow{2}{*}{ No } & \multirow{2}{*}{ Parameter (Parameters) } & \multicolumn{2}{|c|}{ Lokasi (Location) } & \multirow{2}{*}{$\begin{array}{c}\text { Keterangan } \\
\text { (Remark) }\end{array}$} \\
\hline & & Wajo & Sidrap & \\
\hline 1 & $\mathrm{pH} \mathrm{H}_{2} \mathrm{O}$ & 6,58 & 6,72 & Netral (Neutral) \\
\hline 2 & C organik (\%) & 2,64 & 2,28 & Sedang (Medium) \\
\hline 3 & N-total $(\%)$ & 0,12 & 0,16 & Rendah (Low) \\
\hline 4 & P2O5 tersedia (ppm) & 20,65 & 19,26 & Rendah (Low) \\
\hline 4 & $\mathrm{KTK}(\mathrm{cmol} / \mathrm{kg})$ & 24,13 & 20,16 & Sedang (Medium) \\
\hline 5 & $\mathrm{Ca}(\mathrm{cmol} / \mathrm{kg})$ & 6,23 & 5,28 & Rendah (Low) \\
\hline 6 & $\mathrm{~K}(\mathrm{cmol} / \mathrm{kg})$ & 0,254 & 0,12 & Rendah (Low) \\
\hline 7 & $\mathrm{Na}(\mathrm{cmol} / \mathrm{kg})$ & 0,412 & 0,18 & Rendah (Low) \\
\hline 8 & $\mathrm{Mg}(\mathrm{cmol} / \mathrm{kg})$ & 4,02 & 1,18 & Sedang (Low) \\
\hline 9 & Debu $(\%)$ & 40,23 & 22,25 & \\
\hline 10 & Liat (\%) & 37,36 & 56,28 & \\
\hline 11 & Pasir (\%) & 22,41 & 21,47 & \\
\hline 12 & Tekstur & $\begin{array}{l}\text { Lempung berliat } \\
\text { (Clay loam })\end{array}$ & $\begin{array}{l}\text { Lempung liat berpasir } \\
\text { (Sandy clay loam) }\end{array}$ & \\
\hline
\end{tabular}

ma untuk pertumbuhan tinggi dan jumlah cabang (Engelstad, 1997; Rangaswami dan Jolly, 1976). Menurut JOCV (1975) kebutuhan tanaman murbei untuk kalium dan kalsium sedikit, sehingga ketersediaan dalam tanah yang kecil tidak akan menghambat pertumbuhan tinggi dan jumlah cabang. Sedang unsur natrium dan magnesium dibutuhkan tanaman murbei dalam jumlah yang kecil, namun kekurangan unsur magnesium berakibat daun murbei cepat rontok.

Tekstur tanah di Kabupaten Sidrap antara debu, pasir, dan liat $(21,42: 65,61$ : $12,97)$ sangat porus, sehingga aerasi baik. Tekstur tanah demikian sangat mendukung pertumbuhan tanaman murbei. Kedalaman tanah yang dibutuhkan untuk perakaran efektif tanaman murbei berkisar $80 \mathrm{~cm}$, sedang di Kabupaten Sidrap kedalaman tanah mencapai $100 \mathrm{~cm}$, sehingga baik untuk mendukung perkembangan akar tanaman murbei.

Tekstur tanah di Kabupaten Wajo tidak sebaik di Kabupaten Sidrap, perbandingan debu, pasir, dan liat yaitu 40,23 : $37,36: 22,41$ (lempung berliat). Tanah demikian cukup berat untuk diolah dan aerasi kurang baik, untuk tempat tumbuh tanaman murbei harus dilakukan pemberian pupuk kandang. Kedalaman tanah yang dibutuhkan untuk perakaran efektif tanaman murbei berkisar $80 \mathrm{~cm}$, sedang di Kabupaten Sidrap kedalaman tanah mencapai $120 \mathrm{~cm}$, sehingga dapat mendukung perkembangan akar tanaman murbei.

Secara umum tanah di Lawowoi (Kabupaten Sidrap) dapat digunakan untuk budidaya tanaman murbei, namun karena unsur nitrogen, kalsium, dan posfor tersedia dalam tanah rendah sehingga harus dilakukan pemupukan, terutama pupuk yang mengandung unsur-unsur tersebut. Dari sifat fisik tanah di Lawowoi (Kabupaten Sidrap) cocok untuk pengembangan tanaman murbei. Di Sabbangparu (Kabupaten Wajo) kandungan unsur nitrogen, kalsium, dan posfor dalam tanah rendah sebagaimana di Sidrap, sehingga pemupukan harus dilakukan terutama dengan pupuk kandang yang dapat sekaligus memperbaiki tekstur tanah di Wajo yang kurang poros.

\section{KESIMPULAN DAN SARAN}

\section{A. Kesimpulan}

1. Jenis murbei yang cocok dikembangkan di Kabupaten Wajo dan Kabupaten Sidrap adalah Morus khunpai $\mathrm{K}$. karena mempunyai produksi daun tertinggi $(193,67 \mathrm{~g} /$ tanaman di Kabu- 
paten Wajo dan 194,00 g/tanaman di Kabupaten Sidrap) dibandingkan dengan jenis murbei yang lain.

2. Curah hujan di Lawowoi (Kabupaten Sidrap) dan Sabbangparu (Kabupaten Wajo) rendah, sehingga kurang mendukung untuk pertumbuhan tanaman murbei.

3. Tanah di Lawowoi (Kabupaten Sidrap) layak digunakan untuk budidaya tanaman murbei, namun harus ditambahkan pupuk nitrogen, kalsium, dan posfor. Sedang tanah di Sabbangparu (Kabupaten Wajo) untuk budidaya tanaman murbei selain harus dipupuk dengan nitrogen, kalsium, dan posfor, juga harus diperbaiki tekstur tanahnya.

\section{B. Saran}

Daerah persuteraan alam yang beriklim kering (Sabbangparu dan Lawowoi) jenis murbei Morus khunpai K. paling cocok dikembangkan, namun penambahan unsur nitrogen, kalsium, dan posfor harus dilakukan.

\section{DAFTAR PUSTAKA}

Atmosoedarjo, S., J. Kartasubrata, M. Kaomini, dan W. Saleh. 2000. Sutera Alam Indonesia. Yayasan Sarana Wana Jaya.

Engelstd, O.P. 1997. Teknologi dan penggunaan pupuk. Gadjah Mada University Press. Yogyakarta.

Hartoko, B. 2002. Perkembangan kegiatan budidaya sutera alam di Sulawesi Selatan. Prosiding Ekspose Hasil Penelitian Kehutanan. Balai Peneli- tian dan Pengembangan Kehutanan Sulawesi.

Japan Overseas Cooperaration Volunteers. 1975. Texbook of tropical sericulture. Hiroo, Sibuyaki, Tokyo. Japan.

Nabuyuki, M. 1983. Pedoman persuteraan alam. Proyek Kerjasama Pembinaan Persuteraan Alam Indonesia (ATA-72).

Rangaswami, M.N.N. dan M.S. Jolly. 1976. Manual on sericulture. Vol. 1 Mulberry Cultivation. Food Agriculture of The United Nation. Rome.

Samsijah. 1992. Pemilihan tanaman murbei yang sesuai untuk daerah Sindangresmi, Sukabumi Jawa Barat. Bul. Pen. Hut. 547:45-59. Pusat Penelitian dan Pengembangan $\mathrm{Hu}-$ tan. Bogor.

Santoso, B. 1996. Studi fenologi beberapa spesies/varietas murbei. Jurnal Penelitian Kehutanan X (2). Balai Penelitian Kehutanan Ujung Pandang.

Santoso, B. 2002. Upaya pembentukan varietas murbei yang cocok dikembangkan di daerah kering. Prosiding Ekspose Hasil Penelitian Kehutanan. Balai Penelitian dan Pengembangan Kehutanan Sulawesi.

Soeseno, O.H. dan M. Na'iem. 1995. Tanaman murbei di kehutanan Indonesia. Makalah Seminar Nasional Persuteraan Alam Yogyakarta. (Tidak Diterbitkan).

Zobel, B.J. dan J.T. Talbert. 1984. Applied forest tree improvement. John Willey \& Sons, New York. 